\title{
An Empirical Research on the Development Level of the Agricultural Products Logistics in the Region of Sichuan Province
}

\author{
Haoxiong Hong, Chong Wang* \\ College of Management, Sichuan Agricultural University, Chengdu, 610000, China \\ * Corresponding Author: Chong Wang
}

Keywords: Agricultural products, Principal component analysis, Logistics development

\begin{abstract}
Sichuan province is a big province of agricultural products logistics in China. Different population, economy and culture in different cities and states have the own characteristics, forming different agricultural logistics development capabilities. Combined with the principal component analysis, this paper makes use of the macro logistics statistics to analyze the samples of eighteen cities (states) in Sichuan province. The objective is to evaluate the development level and ability of agricultural products logistics in different regions, and give evaluation and suggestions to provide some theoretical support for the government decision-making.
\end{abstract}

\section{Introduction}

Sichuan province is a major province for producing and consuming fresh agricultural products. The development of fresh agricultural products logistics can not only solve the effective supply of agricultural products, but also fully meet the consumer demand to further guide the development of agricultural production.

In the process of development, different regions have formed different logistics development models due to the unique economic conditions and geographical locations. Some economically developed regions have formed an efficient logistics development model. Part of the relatively backward areas only have insufficient infrastructure construction and still maintain the traditional model of logistics development. Some regions are in the middle stage of economic development, and many kinds of logistics modes are used together.

Therefore, we should adopt different logistics policies according to the different development abilities of agricultural products logistics in different regions of Sichuan province to provide favorable environment for fresh food logistics development to better promote the the development of fresh agricultural products in Sichuan province to meet the needs of the residents for fresh agricultural products.

\section{Data Source and Description}

\subsection{Instructions of Samples}

The objects of this study are eighteen cities in the province of Sichuan, whose areas are close to Chengdu, Meishan and Luzhou. They exclude the three autonomous prefectures of Tibetan and Qiang of Aba, Tibetan of Ganzi and Li of Liangshan. The data is mainly derived from the macro data of the Sichuan Statistical Yearbook in 2016.

\subsection{Determination of Indexes}

To scientifically, reasonably and comprehensively reflect the development ability of agricultural products logistics of every city (prefecture), the paper put out the following nine indexes which can explain the development of logistics related capacity indexes (indexes are variables and ordinal variables). They are X1 Per capita gross product, X2 Number of transportation, warehousing and 
post-employment, X3 Public expenditure on transportation, X4 Total highway mileage, X5 Highway freight turnover, X6 Amount of civilian car ownership, X7 Total output value of agriculture, forestry, animal husbandry and fishery, X8 Per capita disposable income of urban residents and X9 Total sales of retail trade.

\section{Empirical Analysis}

This paper uses spass19.0 software to carry out multivariate statistical analysis. In order to ensure the objectivity of the data, all data was adopted from the original data of the 2016 Sichuan statistical yearbook and processed by $\mathrm{Z}$ standardization.

\subsection{Principal Component Analysis}

Correlation test. The data was processed by $\mathrm{Z}$ standardization in spass 19.0 software. Then principal component analysis is performed. First, the result of Table 1 is obtained. The result shows that the Bartlett spheroidal degree test value is $\mathrm{P}<0.001$ and $\mathrm{KMO}=0.810$, indicating that there is a high correlation between variables, which is suitable for factor analysis.

Table 1. KMO and Bartlett tests

\begin{tabular}{crr}
\hline Enough Kaiser-Meyer-Olkin measure & & .810 \\
\hline & Approximate chi-square & 274.864 \\
Sphericity test of Bartlett & $\mathrm{df}$ & 36 \\
& Sig. & .000 \\
\hline
\end{tabular}

Determine common factors. In the process of principal component analysis, factor loading rotation processing method of maximum variance based on the use of software. The results are shown in Table 2, which can be extracted three common factors and reliable. The cumulative variance contribution rate reached $89.974 \%$. From the perspective of characteristic roots, the first two factors are greater than one, so the result was desirable.

Table 2. Total variance of explanation

\begin{tabular}{ccccccc}
\hline & \multicolumn{3}{c}{$\begin{array}{c}\text { Percentage of Variance } \\
\text { of initial eigenvalue }\end{array}$} & \multicolumn{2}{c}{ Percentage of variance of square sum of } \\
rotation
\end{tabular}

Matrix of twiddle load of factors. In order to get a better explanation of factor, we get a rotating component matrix with better explanatory power after rotating the reason submatrix.

Comprehensive score ranking and analysis. The comprehensive scores are calculated as follows:

$\mathrm{F} 1=0.346 \mathrm{X} 1+0.142 \mathrm{X} 2+0.028 \times 3-0.242 \mathrm{X} 4+0.058 \times 5+0.131 \mathrm{X} 6-0.121 \mathrm{X} 7+0.316 \mathrm{X} 8+0.116 \mathrm{X} 9$

$\mathrm{F} 2=-0.208 \mathrm{X} 1+0.079 \times 2+0.187 \mathrm{X} 3+0.358 \mathrm{X} 4+0.143 \mathrm{X} 5+0.092 \mathrm{X} 6+0.274 \mathrm{X} 7-0.145 \mathrm{X} 8+0.109 \mathrm{X} 9$

$\mathrm{F}=0.501 \mathrm{~F} 1+0.499 \mathrm{~F} 2$

According to the above calculation formula and the data after the standardization of the original data, we get a comprehensive score table. 
Table 3. Rotational component matrix

\begin{tabular}{|c|c|c|}
\hline Component & 1 & 2 \\
\hline $\mathrm{Z}_{\mathrm{X}}$ Per capita gross product & .951 & -.084 \\
\hline $\begin{array}{l}\mathrm{Z}-\mathrm{X}_{2} \text { Number of transportation, warehousing and } \\
\text { post-employment }\end{array}$ & .748 & .629 \\
\hline Z-X $\mathrm{X}_{3}$ Public expenditure on transportation, & .521 & .817 \\
\hline $\mathrm{Z} \mathrm{X}_{4}$ Total highway mileage & -.201 & .916 \\
\hline $\mathrm{Z} \mathrm{X}_{5}$ Highway freight turnover & .550 & .705 \\
\hline $\mathrm{Z} \mathrm{X}_{6}$ Amount of civilian car ownership & .732 & .658 \\
\hline $\begin{array}{l}\mathrm{Z}-\mathrm{X}_{7} \text { Total output value of agriculture, forestry, animal } \\
\text { husbandry and fishery }\end{array}$ & .107 & .842 \\
\hline Z-X $\mathrm{X}_{8}$ Per capita disposable income of urban residents & .965 & .105 \\
\hline $\mathrm{Z} \mathrm{X}_{9}$ Total sales of retail trade & .708 & .693 \\
\hline
\end{tabular}

Table 4. Coefficient matrix of component score

\begin{tabular}{llcc}
\hline \multicolumn{1}{c}{ Component } & 1 & 2 \\
\hline $\mathrm{Z}-\mathrm{X}_{1}$ & Per capita gross product & .346 & -.208 \\
$\mathrm{Z}-\mathrm{X}_{2}$ & Number of transportation, warehousing and & .142 & .079 \\
post-employment & & \\
$\mathrm{Z}-\mathrm{X}_{3} \quad$ Public expenditure on transportation, & .028 & .187 \\
$\mathrm{Z}-\mathrm{X}_{4} \quad$ Total highway mileage & -.242 & .358 \\
$\mathrm{Z}-\mathrm{X}_{5} \quad$ Highway freight turnover & .058 & .143 \\
$\mathrm{Z}-\mathrm{X}_{6} \quad$ Amount of civilian car ownership & .131 & .092 \\
$\mathrm{Z}-\mathrm{X}_{7} \quad$ Total output value of agriculture, forestry, animal & -.121 & .274 \\
husbandry and fishery & & \\
$\mathrm{Z}-\mathrm{X}_{8} \quad$ Per capita disposable income of urban residents & .316 & -.145 \\
$\mathrm{Z}-\mathrm{X}_{9}$ Total sales of retail trade & .116 & .109 \\
\hline
\end{tabular}

Table 5. Table of comprehensive scores of all areas

\begin{tabular}{ccccccc}
\hline City & \multicolumn{2}{c}{$\mathrm{F}_{1}$} & \multicolumn{2}{c}{$\mathrm{F}_{2}$} & \multicolumn{2}{c}{$\mathrm{F}$} \\
& Score & Rank & Score & Rank & Score & Rank \\
\hline Chengdu & 2.98091 & 1 & 2.50657 & 1 & 2.744214 & 1 \\
Mianyang & -0.25737 & 11 & 0.56118 & 4 & 0.151086 & 2 \\
Nanchng & -1.16755 & 18 & 1.36151 & 2 & 0.094451 & 3 \\
Dazhou & -0.97162 & 16 & 1.04475 & 3 & 0.034549 & 4 \\
Yibing & -0.41353 & 14 & 0.41354 & 5 & -0.00082 & 5 \\
Luzhou & -0.0394 & 8 & 0.02632 & 9 & -0.00661 & 6 \\
Leshan & 0.16376 & 5 & -0.24488 & 10 & -0.04015 & 7 \\
Deyang & 0.3733 & 3 & -0.5952 & 15 & -0.10998 & 8 \\
Ziyang & -0.30751 & 13 & 0.04648 & 8 & -0.13087 & 9 \\
Panzhihua & 1.77312 & 2 & -2.04575 & 18 & -0.1325 & 10 \\
Meishan & 0.10649 & 6 & -0.5882 & 14 & -0.24016 & 11 \\
Guangyuan & -0.9346 & 15 & 0.40497 & 6 & -0.26615 & 12 \\
Zigong & 0.34533 & 4 & -0.88838 & 16 & -0.27029 & 13 \\
Guangan & -0.19972 & 9 & -0.37569 & 11 & -0.28753 & 14 \\
Neijiang & -0.20656 & 10 & -0.38784 & 12 & -0.29702 & 15 \\
Suining & -0.29348 & 12 & -0.48387 & 13 & -0.38848 & 16 \\
Bazhong & -0.99444 & 17 & 0.15771 & 7 & -0.41952 & 17 \\
Ya’an & 0.04287 & 7 & -0.91323 & 17 & -0.43422 & 18 \\
\hline
\end{tabular}




\subsection{Summary}

In general, we can find the following two rules from the analysis of the comprehensive scores of all the regions. First, compared to the other 17 states and cities, the development ability of Chengdu agricultural product logistics is much higher than the other regions. Both the scale of Chengdu's economic development and the input factors of agricultural product logistics rank the top in Sichuan. Second, due to the high input elements of agricultural products logistics, the cities with backward economic development scale factors, such as Nanchong, Dazhou and Yibin, rank well in the agricultural product logistics development abilities. The overall situation of Mianyang which ranked second is also outstanding. Because of its more developed industrial system, the development of economy and logistics system makes its logistics development capability of agricultural products second only to Chengdu. The economic status and input factors of agricultural products logistics in Luzhou, Leshan and Ziyang are all good. Therefore, the ranks of agricultural products logistics development are all at the top. Deyang and Zigong scored highly in terms of economic scale factor. The actual economic conditions in Sichuan province were also good, but their scores in agricultural products logistics inputs were very low. For example, Deyang's total highway mileage is low. The road freight turnover is not high, the road transport is relatively weak and the overall agricultural products logistics capability is only ranked eighth. And Zigong is more backward, whose road transportation, traffic construction investment is less than other states. Therefore, it has influenced its overall ranking in the logistics capacity of agricultural products. In addition, the output value of agriculture, forestry and animal husbandry in Zigong is also very low, resulting in the logistics development of agricultural products languished in 13th. Due to the special geographical position of Panzhihua, the age structure and sex ratio of urban population have been greatly influenced by the recession of the heavy industrial industry. With just one million population, agricultural production value in recent years of Panzhihua city grow rapidly, which can exceed the provincial planning tasks. However, the total quantity is at the bottom compared to other cities. In the aspect of road transportation and freight volume and other logistics input factors, Panzhihua also ranks behind. Its agricultural product logistics development ability ranked the top ten. Meishan, Guang'an, Guangyuan, Neijiang, Suining and Ya'an are all the low-ranking cities. Their economic scale and the input factors of agricultural products logistics are relatively backward compared to the other states and cities in the province. The Bazhong city ranking the seventeenth has lower economic scale and less transportation capacity. Therefore, the overall agricultural product logistics development ability is backward, but rom the whole province perspective, its agricultural development is still good.

\section{Deficiencies and Prospects}

This paper only selected eighteen cities in Sichuan province. Considering that the economic and regional area of the three autonomous prefectures are objectively special compared to the other eighteen cities, they are not compared in the samples. In addition, because of the limited access to macro index data, we cannot add all indicators that can reflect the development capacity of agricultural products logistics into analysis. We can only choose nine representative indicators for evaluation and analysis, and the results are only for reference and discussion.

It is hoped that more accurate indicators can be selected in the next research. We combine them with a more perfect analysis method to make a more objective analysis and discussion for all the cities and prefectures, including three autonomous prefectures in Sichuan province.

\section{References}

[1] Yang A'ni. The Analysis of the Development of Domestic Fresh Agricultural Products Logistics [J]. Logistics Sci-Tech, 2012(5): 61-63.

[2] Shu Zhuangjian. Empirical Study on Jiangsu Regional Logistics Capacity Based on Factor Analysis [J]. Logistics Technology, 2013, 32(4): 192-194+210. 
[3] Ding Ran, Han Wenjing. Mode and Operational Mechanism of Hebei Fresh Farm Produce Distribution [J]. Logistics Technology, 2011, 30(7): 70-72.

[4] Yang Songxia, Lv Enli, Lu Huazhong, et al. Present situation analysis on litchi cold chain logistics [J]. Guangdong Agricultural Sciences, 2012(16): 196-199.

[5] Yang Songxia, Lv Enli, Lu Huazhong, et al. Effects of different fresh-keeping transportation modes on quality of litchi fruit [J]. Transactions of the Chinese Society of Agricultural Engineering (Transactions of the CSAE), 2014, 30(10): 225-232.

[6] Wang Xiaoli. Empirical Study on Urban Logistics Capacity Measurement Based on PCA [J]. Logistics Technology, 2013, 32(5): 284-286.

[7] Srimanee Y, Routray J K. The fruit and vegetable marketing chains in Thailand: policy impacts and implications[J]. International Journal of Retail \& Distribution Management, 2012, 40,(9): 656-675.

[8] Manos B, Manikas I. Traceability in the Greek fresh produce sector: drivers and constraints[J]. British Food Journal, 2010, 112,(6): 640-652. 